THE LIMITATIONS OF THE ECONOMIC POINT OF VIEW

John $\mathrm{K}$. Whitaker*

University of Virginia

Discussion Paper 83.18

Octöber 1983

ISSN 0811-6067

* Visiting Bateman Lecturer, Department of Economics, The University of Western Australia, July 1983. 
The Limitations of the Economic Point of View*

$$
\text { by }
$$

John K. Whitaker

University of Virginia

* This is the text of the Bateman lecture delivered at the University of Western Australia, July 25, 1983. I am grateful to the Bateman trustees for their financial support and to the Department of Economics of the University of Western Australia for making my stay in Perth so enjoyable. Apart from a few minor rewordings, I have left the text as it was read, but have added footnotes and references. 
grips with important issues. If we feel these attempts are wrong or misguided we should be able to give adequate reasons for this feeling and not a merely emotional response. 1

The first thing I want to do is to outione the general character of what I perceive to be the economist's approach, or as I will term it the economic point of view. I will try to catalogue the limitations of this approach in dealing with the general class of problems universalty agreed to be economic, such as the determination of prices and incomes. With an idea of these Timitations in mind we might be better placed to see which kinds of intrusion into neighbouring fields are likely to be successfur and which are likely to fail. Applications which involve the kind of problem economics has handled well in its own area are more likely to succeed than applications involving the sorts of difficulties the economic approach has already found it hard to cope with when handling specifically economic issues.

I then go on to consider one particular line of extension of economics outside its traditional boundaries. This is the attempt, associated particularly with Gary Becker of the University of Chicago, to subject to an economic mode of analysis various household decisions or actions such as marriage, conception, suicide, churchgoing, etc. This general approach is sometimes referred to as "the new home economics." It is a brand of what Becker calls "the economic approach to human behaviour." 2 My impression is that this is the most controversial and scepticaliy received of the various forays into new territory that economists 
This generat approach to economic phenomena is, of course, broadiy present in Adam Smith and was developed fairly fully by the neoclassical economists, especially Walras and Pareto. The remakable thing, as Smith discerned, is that the apparently chaotic and uncoordinated pursuit of individual self interest provides a robust basis for social organization. Moreover the form of social organization it gives rise to has various attractive features, especially its flexibility in adapting to change, its decentralization of responsibility and power, and its ability to eliminate certain kinds of inefficiency in resource allocation. I imagine that everyone who has taken a course in ecnomics was fascinated on first discerning the vision of a complex selfregulating system of markets, harnessing self interest to produce social order. And this vision is still at the center of what I have called "the economic point of view."

What I would regard as essential features of this point of view are:

i) The primacy, independence and stability of individual preferences.

ii) The assumption of rational behaviour, in the sense that individuals act deliberately and persistently to further their own ends in the light of the information they possess about the possibilities they face.

iii) The assumption that individuals are adequately informed about the possibilities they face. They understand the current and future consequences of the 
poker player knows, these are notoriously difficult to predict, and even more difficult to characterise in general terms relevant to any opponent. I would view the problem as ultimately one in applied psychology, calling for experiment rather than further deductive enquiry.

On the face of it, the economist's treatment of uncertainty seems to be one of his success stories. Using the concepts of subjective probability and expected utility economists and statisticians have developed an appealing and elegant theory of how individuals make decisions and react to new information in conditions of uncertainty. Unfortunately, this theory--although doubtless appropriate for some problems-is not generally confirmed by experimental evidence. ${ }^{6}$ Moreover, the theory seems too tidy and elegant by half in the way it tames the imponderables of the future. This point was forcefully made by $3 . M$. Keynes, himself a pioneer of the subjective probability theory:

The future never resembles the past-as we well know. But generally speaking our imagination and our knowledge are too weak to tell us what particular changes to expect. We do not know what the future holds. Nevertheless, as Tiving and moving beings, we are forced to act. Peace and comfort of mind require that we should hide from ourselves how little we forsee. Yet we must be guided by some hypothesis. We tend, therefore, to substitute for the knowledge which is unattainable certain conventions, the chief of which is to assume, contrary to all likelihood, that the future will resemble the past. This is how we act in practice. Though it was, I think, an ingredient in the complacency of the nineteenth century that, in their philosophical reflections on human behaviour, they accepted an extraordinary contraption of the Benthamite School, by which all possible consequences of alternative courses of action were supposed to have attached to them, first a number expressing their comparative advantage, and second$1 y$ another number expressing the probability of 
socially conditioned. Economists might ignore this if they are interested in short periods, for which tastes may be assumed to change little, or if they believe there is no feedback from the economic outcome they are analysing to the social conditioning factors. The latter belief would seem difficult to sustain. A particularly prominent victim of recognizing this would be traditional welfare economics which is based on the exogeneity and primacy of the particular set of individual preferences associated with the status quo. Recognition of a sociallyconditioned element in preferences would imply that the economist"s reductive explanation of phenomena to consequences of the preferences individuals possess and the constraints they face, is only a proximate explanation. The next question is "why do individuals have the preferences they have?"

Mention of constraints leads me to the second error of ommission to which economists are prone. This is the neglect of social constraints on individual action, such as those represented by moral codes, group loyalties or coercive relationships. To the extent that economists recognize such constraints they seek to explain them reductively, as I mentioned previously. If they cannt do this they tend to ignore the constraint, or at least apologize for the ad hoc or "sociological" (even worse) element in their theory. But economists are unable to explain without resorting to "ad-hoc-ery" such a simple phenomenon as the willingness of individuars to vote when the electorate is large so that the individual"s vote is insignificant with probability almost one. ${ }^{9}$ And it still remains to be seen 
utility maximisation framework, but may explain too much in the sense that no restrictions on behaviour may be left.

The accusation that economists assume all decisions to be made in a spirit of cold-blooded calculation is, I suspect, a consequence of the practice of speaking of individuals as maximising utility or profit. This suggests explicit and pennypinching balancing of costs and benefits at the margin of decision. In fact this may be more in the nature of colourful metaphor than behavioral description. Indeed, the economist typically eschews all behavioral connotations and views individuals as "black boxes" whose inner workings remain mysterious. What he minimally assumes is that:

a) individual preferences are consistent, in the sense that if an individual prefers $\alpha$ to $\beta$ and $\beta$ to $\gamma$ he should not prefer $\gamma$ to $\alpha$

b) preferences are stable for the period in question

c) by whatever unexplained combination of agonizing, deliberation, rule of thumb or guesswork, the individual, when faced with a set of possible choices, finishes up choosing one very close to that his preferences indicate he would prefer over the others. As it is frequentiy said, he acts as if he maximized a utility function representing his preferences.

At this point let me interject a few remarks on the general topic of the "as if" approach to human behaviour. You may recall 
praxeology, 13 but such challenges have had little impact on strongly entrenched attitudes.

The economist gets away with an incomplete and descriptively unsatisfactory formulation of human behaviour because it suffices for his purpose and forms an integral and manageable component in a larger theoretical structure. It is the value of this larger structure, if it has any, that justifies his shortchanging of the analysis of the individual. To say that the value of the complete structure comes entirely from its predictive power would be misleading if predictive power is interpreted in a narrow sense. I would prefer to speak of explanatory power because the understanding conveyed by economic theory is often more akin to philosophical explanation than to scientific knowledge.

If one"s goal were simply to predict the way in which an individual or group of individuals would respond to certain stimuli, it is by no means clear that the economist's short-cut approach to behaviour will be the best one for the job. The success of economics as a body of knowledge (if it is a success) does not imply this, because the need to retain tractability and coherence has inevitably imposed severe constraints on the choice of component elements of the entire structure and better alternatives may be available for more restricted purposes.

When the economist claims to "explain" differences in behaviour between individuals, he doesn"t claim to provide insight into the mental processes by which individuals come to differing decisions. He simply means that the can predict differences in 


\begin{abstract}
money prices or imputed shadow prices, repeated or infrequent decisions, large or minor decisions, emotional or mechanical ends, rich or poor persons, men or women, adults or children, brilliant or stupid persons, patients or therapists, businessmen or politicians, teachers or students 14
\end{abstract}

He believes that

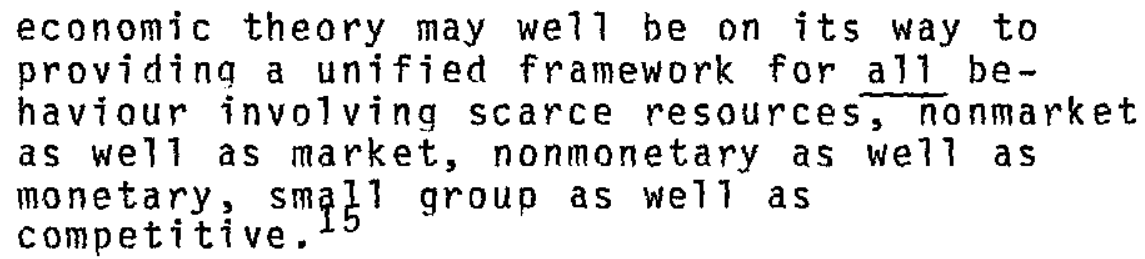

He characterizes the heart of the economic approach as "The combined assumptions of maximizing behavior, market equilibrium, and stable preferences, used relentiessiy and unflinchingly."16 Actually, market equilibrium may not be involved in all applications, as we shall see, although market opportunities may enter in the weaker sense of offering individuals the possibility of transacting on fixed terms. Thus we are left with maximisation and stable preferences as the really fundamental aspects of the economic approach. On maximisation he observes that the economic approach

does not assume that decision units are necessarily conscious of their efforts to maximize or can verbalize or otherwise describe in an informative way reasons for the systematic patterns in their behavior. 17 
irrational behavior, unnecessary ignorance, folly, ad hoc shifts in values and the like, which is simply acknowledging defeat in the guise of considered judgment. 21

What he fails to recognize, or at least emphasize, is that there may be similar temptations to tautology in characterising the opportunities individuals face for such vaque desiderata as prestige or benevolence. He does, indeed, recognize that the approach may be made tautological by the invocation of unspecified decision costs:

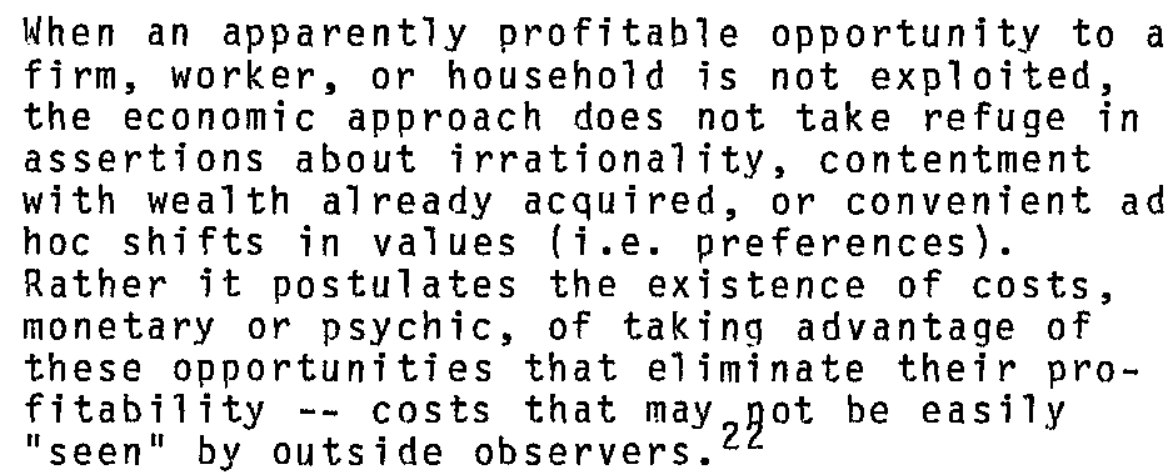

But he still appears to feel that such a tautological closure leaves a theory which retains predictive power. He also feels that the economic approach "provides a valuable unified framework for understanding al1 human behaviour," 23 a framework into which the contributions of other behavioural and social scientists may be fitted without conflict. The latter is certainly true if the economic approach is interpreted tautologically, but then how valuable can it be? On the other hand, any refutable formulation of a specific case can presumably be refuted, and might lose out to a quite different approach coming from some other discipline. So, explanatory success of the economic approach, in 
deciding on the allocation of their time and resources. The crux of their model is described as follows
most religions promise their members some form of an afterlife. Furthermore, the expected afterlife benefits are often viewed by in- dividuals as being at least partially related to their lifetime allocation of time to reli- gious activities. This suggests that house- hold participation in church-related activities should be analyzed in the context of a multiperiod household-allocation-of-time model which allows for "afterlife consump- tion," with this variable being at least par- tially a function of the household"s invest- ment of members" time in religious activities during their 7 ifetime. 2

This "salvation" motive, as it is termed may be supplemented by a "consumption" motive (people just like to go to church) or a "social pressure" motive lgoing to church wilt help you succeed in business). But these additional motives get little attention. The couple is assumed to know (or believe in) the production function by which church going is converted to aftertife consumption. They also know that they will share equally in the 3atter and that they will have a subjective rate of time preference in the afterlife, so that infinite utility stream received there will have a finite present value. They are able to compare this present value with the utility of consumption occuring at any date in the present life. The available time in each period can be allocated freely between churchgoing, work in the market, or household activity. Maximization of utility (both here and hereafter) subject to the usual constraints, current and expected wage rates, etc., yields optimal current and planned 
At this point all we can do is remind ourselves that this is an "as if" model which will have to be judged by its success in prediction - to be precise in predicting variation in churchgoing behavior between individuals or groups of individuals. Predictions are offered for average behaviour of the populations of each of 49 states in the USA and for a sample of 1504 adults in the USA. The data are not ideal and the brute realities call for the inclusion of many extra explanatory variables on ad hoc grounds. What then is left of the model and under what conditions would we be led to reject it? It is not clear, but one is somewhat surprised to learn from the authors that the results overall provide "strong support" for their model.27 The support it appears comes from the significance of age, sex and "belief in an afterlife" as influences on churchgoing, even after other control variables are added. And the state data do tend to suggest that low-wage states are more religious lalthough I doubt whether all the considerable socio-cultural differences between low and high wage states are adequately controlled forl.

But what if these results had come out differently? Would the model have been rejected, or would some of the quite arbitrary supplementary assumptions have been adapted to the facts? One suspects the latter. But that would mean the model was not predictive after all, so that its value would have to be justified by the insight it gives into "how and why" people go to church -- not something on which I would give it high marks. Its defects in this regard are I think obvious. It takes a situation to which Keynes" strictures about our lack of knowledge of the 
is devoted to working for pay. But, as Fair observes, the paramour could be replaced by a social club, or even a church group, and the theory would be essentially the same. It could hardiy be indicated more pointedly that the theory is devoid of significant psychological or sociological content and concerned only with a formal representation of choice outcomes.

The theory involves three persons, termed Spouse, Individual and Paramour. They may be of either sex, although perhaps spouse and Individual might be assumed to be of opposite sex. The theory focuses on Individual"s decision to allocate his or her time. Individual is supposed to make this decision on the presumption that the actions of Spouse and Paramour will be quite unaffected by Individual's choice. IOddly, Paramour and Individual may spend quite different amounts of time on the affair.) The consequences of the theory are summarised by Fair:
Time spent with paramour is seen to be a func- tion of [individual"s] wage rate, the price level, [individual"s] nonlabor income, the time spent by the spouse in the marriage, the value of goods supplied by the spouse to the marriage, the time spent by the paramour in the affair, the value of goods supplied by the paramour to the affair, and any other variables that have an effect on the utility received from the marriage or on the utility
received from the affair.

The theory as formulated does impose certain restrictions on the way Individual"s behaviour responds to changes in the parameters he or she faces. However the statistical testing which follows is unable to test for the fulfillment of these restrictions. It 
more people involved would seem crucial, so that the situation might be more convincingly viewed as one of strategic interaction. 33 This is a kind of problem that economists have not succeeded in handing adequately. But extramarital affairs often are very unlike grocery shopping and can produce guilt, remorse, depression, and other strong psychological reactions, which suggest that the decision was hardly one of a calmiy considered barancing of competing attractions based on adequate knowledge of the consequences. On such aspects of marital infidelity one would learn more from reading John Updike than from an economics text.

I will deal very briefly with my third example, a paper on "The Economics of Suicide" by Hamermesh and Soss. 34 They readily admit that:

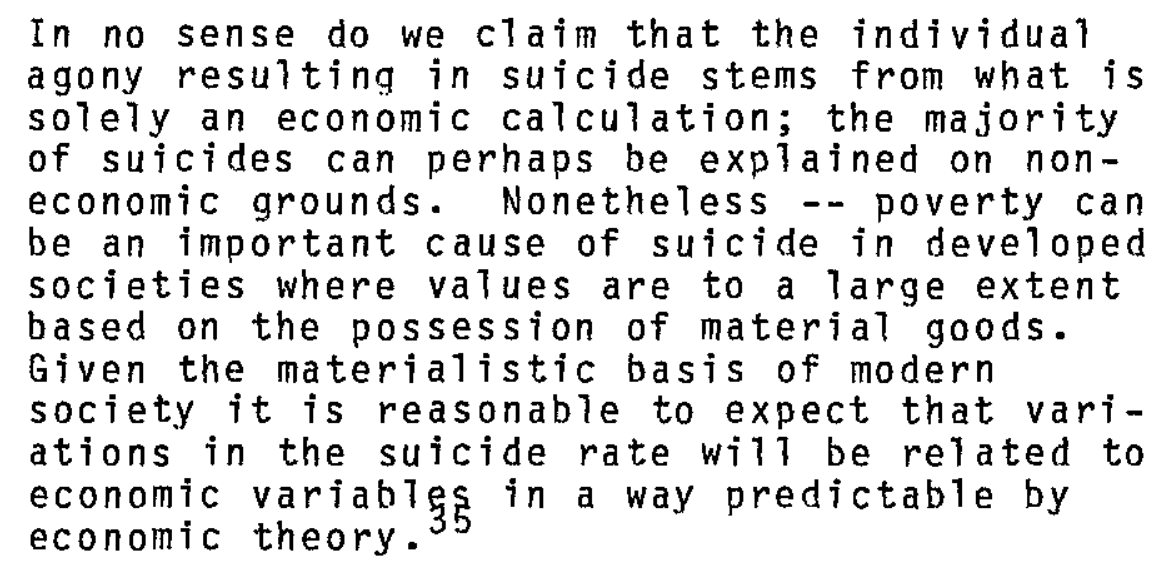

Despite this, they present a model which implies that everyone will commit suicide at any age if made sufficiently poor, and conversely could always be induced not to commit suicide by being given enough money. Non-economic variables enter this decision 
may be induced by the experience of adverse economic circumstances, leading to an action that is not rational in any plausibie sense.

Had there been more time I would have liked to expatiate on my fourth and last example. Gary Becker"s paper, "A Theory of Marriage," is the most impressive and intriguing of the four. 36 He observes that marriage is voluntary and that there are many potential mates, so that there is a kind of marriage market, although not usually an explicit one. He assumes, however, that the outcome will be the same as it would have been with an explicit market which operated perfectly to produce a unique "sorting" or pairing of spouses. Marriages are made, not in heaven, but by the invisible hand.

The theory is premissed on the assumption that a couple produces as a team an output of intangibles which can be reduced to a scalar and compared between households. The unique equilibrium sorting of mates is the one maximising the total amount of this output over all households. To achieve this sorting it is necessary for each couple to have a contract, explicit or implicit, governing the division of the couples output between themselves. Each individual "joins" the marriage which provides him or her as an individual with the most output. The situation is exactly analogous to one with a marketed output in which the wives are hired by the husbands at specified wages to assist with production and a competitive equilibrium is achieved. To soften the corners, Becker introduces the possibility of "caring," as he terms it. Couples who care are more productive as a team. Thus, 
market that is very far from achieving a competitive equilibrium. And the analysis of markets in disequilibrium is not one of the success stories of economics.

Let me come to a rapid, and probably vapid, conclusion. Some people doubtless regard as outrageous the intrusion of economists into aspects of 1 ife and human behaviour remote from the marketplace. Their view of economists is as people who know the price of everything and the value of nothing. Such attitudes are sometimes based on the mistaken belief that the economist"s writ runs only where there are explicit prices and markets. I hope to have made clear that this is not so, and that shadow prices, opportunity costs, and implicit markets may still have significant functions even though no money changes hands. 38

A more serious complaint is that some actions, beliefs or commitments are not amenable to the pecuniary motive: "I would not do this, or prostitute myself to that, at any price" is a not uncommon kind of remark. The economist would describe such cases as involving lexicographic preferences and admit that these might well exist. Even then, the concept of opportunity cost may arise in the choice between goals that are incommensurable with the pecuniary ones. 39 But though it may not always be true that "every man has his price" most of us would be tempted if the price were high enough -- "a million won"t do, here take $10 \mathrm{mil-}$ lion and think of all the good you could do!" I suspect that the segregation of other aspects of behaviour from the action of pecuniary motives is not as watertight as many people would like to think. 
If the traditional economist"s approach to explaining human behaviour has its limitations, what kind of modifications and extensions might extend our grasp? I confess that I don "t have a firm idea, but would guess that it will prove necessary to peer inside the "black box" of economic man and place more emphasis on motive or intention and on the processes by which decisions are made or actions precipitated. The economist may have an important part to play in such developments, but can hardly expect to rule the roost. 
20. Ibid., p. 5 .

21. Ibid., pp. 11-12.

22. Ibid., p. 7 .

23. Ibid., p. 14 .

24. See Blinder (1974).

25. Azzi and Enrenberg (1975).

26. Ibid., p. 28 .

27. Ibid., p. 51 .

28. Fair (1978).

29. Ibid., p. 47 .

30. Ibid., p. 46 .

31. Ibid., p. 60 .

32. Ibid., p. 60 .

33. As Fair himself notes, p. 51 .

34. Hamermesh and Soss (1974).

35. Ibid., p. 97 .

36. Becker (1973-4).

37. Becker (1976), p. 10 .

38. This point is emphasized by Posner (1980).

39. On this see Nutter (1979).

40. A fourth and rather different line of objection to the economic analysis of individual behaviour is that it denies individual freedom and creativity and ignores the fact that 1 ife is a search for values rather than a realisation of them. This kind of objection is exemplified in the writings of Knight and Shackle. See for example McKenzie (1979). On this view, individual behavior is predictable only to the extent that individuals choose it to be so.

41. Becker (1976) contains some of Becker"s seminal contributions to these topics. 
Keynes, John Maynard (1937), "Some Economic Consequences of a Declining Population," Eugenics Review (March 1937), reprinted in his CollectedWorks, Vol. XIV (London, Macmilian, $1972), 124-133$.

Kirzner, Israel (1960), The Economic Point of View (Princeton, Van Nostrand, 1960$\}$.

Machlup, Fritz (1972), "The Universal Bogy" in Peston, Maurice and Corry, Bernard (eds.), Essays in Honour of Lord Robbins (London, Weidenfeld and Nicotson, 1972).

Margolis, Howard (1982), Selfishness, Altruism and Rationality: A Theory of Social Choice TCambridge, Cambridge University press, 1982).

McKenzie, Richard B. (1979), "The Non-rational Domain and the Limits of Economic Analysis," Southern Economic Journal, 46 $(\mathrm{J} u 7 \mathrm{y}, 1979), 145-157$.

NerTove, Mark (1974), "Household and Economy: Toward a New Theory of Population and Economic Growth, Journal of Political Economy, 82 (March/Apri), 1974: SuppTement), 200-218.

Nutter, G. Warren (1979), "On Economism," Journal of Law and Economics, 22 (oct., 1979), 263-268.

Posner, Richard (1980), "Anthropology and Economics," Journal of Poititical Economy, 88 (June, 1980), 608-616.

Simon, Herbert A. (1978), "Rationality as Process and Product of Thought," American Economic Review, 68 (May, 1978), 1-16.

Sen, Amartya K. (1982), "Rational Fools: A Critique of the Behavioural Foundations of Economic Theory, "Chapter 4 of his Choice, Welfare and Measurement, (Oxford, Blackwe11, 1982).

Wicksteed, PhilTip H. (1933), The Commonsense of Politica) Economy (London, Routledge, 1933: a reprint of the 1910 ediEiont. 


\section{The Limitations of the Economic Point of View}

Economists are well known, if not notorious, as the Napoleons of social science - or perhaps one might better refer to them as Alexanders, always sighing for new fields to conquer. Certainly, the last quarter century has witnessed a large-scale intrusion of economics into neighbouring areas of social enquiry. The economic approach has by now entered significantly into law, political science, anthropology, sociology and psychology. This unwonted and perhaps unwanted intrusion of economics has not been matched by an increased interest on the part of economists in learning more about the approaches traditional in these areas. The economist"s idea of interdisciplinary work is to enter a new area of application and apply his own approach from scratch. There are, of course, exceptions to this, as to any such generalisation, but I am trying to convey the general attitude of economists as a breed.

Now I am an economist and have pride in my subject and its achievements, which I believe are considerable leven though macroeconomics may hue been oversold as a policy tool in the $1960 \mathrm{~s}$ and $1970 \mathrm{~s})$. Yet some of the more extreme forays into neighbouring fields give me misgivings, as I believe they do the majority of economists. What I seek to do tonight is to articulate these misgivings. It is all too easy to dismiss work one finds unappealling with the words "nonsense" or "idiocy." But we are dealing with an intellectually serious attempt to come to 
have undertaken in recent years. Without attempting a final judgement I will try to make clear the kinds of objections one might levy against this sort of application of economic tools and concepts.

Let me turn then to an attempt to characterise briefly the "economic point of view." 3 A fundamental aspect of it is that it is atomistic. That is, it regards economic phenomena as the outcome of many independent decisions made by the individuat actors on the economic stage. (This is sometimes termed methodological individuatism.) These individual actors comprise basic atoms in a further sense. Each is assumed to have preferences which are independent of the overall outcome. And each individual pursues a course of action devoted primarily to his self interest (broadly conceived) with 1 ittle or no regard for the overall outcome.

The actions an individual can take are constrained by technical possibilities and institutional arrangements. The technical possibilities are usualiy taken as given and form a further element in the data which will explain the overall outcome. Traditionally economists have paid little attention to social institutions beyond taking for granted the basic institutions of property and markets. In recent years it is true that there has been an increased interest in treating institutional arrangements as the consequence of agreements of groups of individuals, achieved either voluntarily (e.g. wage contracts) or through government (e.g. provision of public goods). But such agreements are, if possible, reductively explained in terms of individual self interest, and so do not serve as fundamental data. 
various possible courses of action, not perhaps perfectly, but with sufficient prevision to produce a broad consilience of intended and actual consequences on average. 4

These three features seem to me to lie at the heart of economists" attempts to explain individual behaviour and its social effects, whether they are dealing with strictly economic problems or making the kind of extra-economic foray adverted to above. Now let me try to catalogue the more conspicuous failures and limitations this general approach has met with in the home territory of economists.

Within its own frame of reference, I would see the main failures of economics to be the inadequacy of the treatment of (i) strategic interaction,

(ii) uncertainty,

(iii) disequilibrium.

Ever since Cournot wrote on duopoly in $1838^{5}$ there have been attempts to develop a theory of the interaction of small numbers of economic actors. More recently, this search for satisfactory formalisations has received the aid of game theory. But my judgement is that we are still far from a satisfactory explanation and understanding of these complex problems--even of something as simple as the prisoners" dilemma. The difficulty is with the assumption that each individual knows the possibilities he faces. With small numbers these possibilities depend on the strategic response of others to the individual's actions. As any 
their following from the course of action in question; so that multiplying together the numbers attached to a11 the possible consequences of a given action and adding the results, we could discover what to do. In this way a mythical system of probable knowledge was employed to reduce the future to the same calculable status as the present. No one has ever acted on this theory. But even today I believe that our thought is sometimes influenced by some such pseudorationalistic notions.7

Such views seem to have fallen on deaf ears, despite Keynes" impact on the subject in other ways. He would doubtiess be astonished to find that what he might have termed the "Benthamite fallacy" is firmly in the saddle once more.

The third failure, the inadequate treatment of disequilibrium seems to me less serious. I do not think there is anything fundamentally wrong with our approach. It is just that the analysis of market disequilibrium becomes very complex and intractable, so that no general theory has been developed and the emphasis has been on special cases which provide onty examples.

Besides the errors or failures of commission just described there seem to be important errors of ommission due to the economist"s self-imposed blinkers. The most glaring is the almost entire neglect of the question of how preferences are formed. Economists simply take individuals" preferences for granted and go on from there. Mark Nerlove observes at one point that he has not mentioned the formation and change of preferences "lest I be excommunicated from the economics profession! It is virtualiy part of the definition of what an economist is that he takes tastes as given." 8 Now, except perhaps in terms of very basic needs, it seems probable that individual preferences are strongly 
whether a sociologically-uncontaminated treatment of labor markets is tenable (I could again invoke keynes here, this time on the question of the stickiness of money wages.)

Economists are often accused of another kind of Timitation, but this I feel to be only partly justified. The accusation is that they work with an erroneous and artificial view of human motives and actions, treating them as entirely self-regarding and calculated. This is the familiar bogy of homo economicus-economic man (or women)--which it has been incessantly complained (since Carlyle at least) is a caricature of, if not a libel on, flesh-and-blood man. This is misleading, first because economists need make no presumption that preferences are completely egoistic. They simply take preferences as whatever they are. No difficulties arise if an individual prefers to devote his resources to his children or to charity rather than to his own consumption. As Wickstead emphasized, the crucial requirement for much of economic theory is non-tuism, i.e. neither party to a transaction should be concerned with the interests of the other party, but may well be pursuing the interests of someone other than himself.10 It is even possible to analyse cases of reciprocal altruism with economists" tools. On the other hand, Howard Margolis has stressed in a recent book that there are many aspects of altruistic behaviour which are difficult to explain without supposing that individuals are public spirited, valueing the sheer act of giving and participating as well as its effects. 11 This too might be accommodated into the economist"s 
that Milton Friedman, in his essay on positive economics, 12 took up the case of predicting the distribution of leaves on a tree. He supposed (and it may well be true) that this distribution may be predicted well by assuming that the tree places its leaves to maximize the amount of light absorbed. It seems mmost unlikely that the tree makes explicit calculations to this effect, so there must be some unexplained process underlying the result.

If our interest was simply in predicting leaf distribution we might be willing to leave things there. But a plant physiologist, desiring to understand how trees function, would not find the maximization theory very interesting. He would look for a more convincing, and in some sense more realistic, description of the processes giving rise to the leaf distribution. Indeed, even someone interested only in prediction might wish to explore such richer approaches in the hope that they might lead to better prediction ultimately. Analogously, the economist, concerned simply to predict behavioural outcomes, will be content with an "as if" theory giving little insight into how and why these decisions are made. While the psychologist (say) who is concerned mainly with this "how and why" will find the economist"s theory almost entirely devoid of interest - unless indeed its explanatory power clearly dominates other alternatives.

Economists have virtually expunged the notions of purpose, intention and decision process from their vocabulary, resting content with a formulation which considers only the outcome of decisions. This has not been entirely without complaint from within, especially from the neo-Austrians with their calls for 
individuat response as a consequence of differences in the preferences of, or the opportunities facing, the individuals. The presumption that individuals do in fact find the preferred element in their opportunity set is a kind of unexplained middle axiom or maintained hypthesis in such an argument. It may not be factually justified, yet still may lead to predictions that are acceptably accurate for some given purpose.

This kind of "explanation" of differences in individual behaviour is not valueless. To say that you drink more wine than I do because you can buy it more cheaply, or alternatively because you like it better, conveys meaning. But such statements give little insight into the social, psychological and physiological bases for the difference in the amounts we consume. Moreover, the value, such as it is, of such statements is entirely dependent on our ability to identify individual preferences and opportunities (or at least differences in them) independentry of the behaviour being explained. Otherwise the explanation is not an explanation but a statement of beliefs. The theory is not a refutable theory,but a tautology.

Let me retreat at this point from the quagmire of methodological discussion and turn to the economic approach to human behaviour and its application to the family. I will start by considering Becker"s general description of this approach and then take up four particular applications of it. Becker claims that the economic approach is: 
In other words, this is an essentialiy unexplained part of the approach, or a middle axiom as I called it earlier. His justification for assuming constancy of preferences is rather 1 ame:

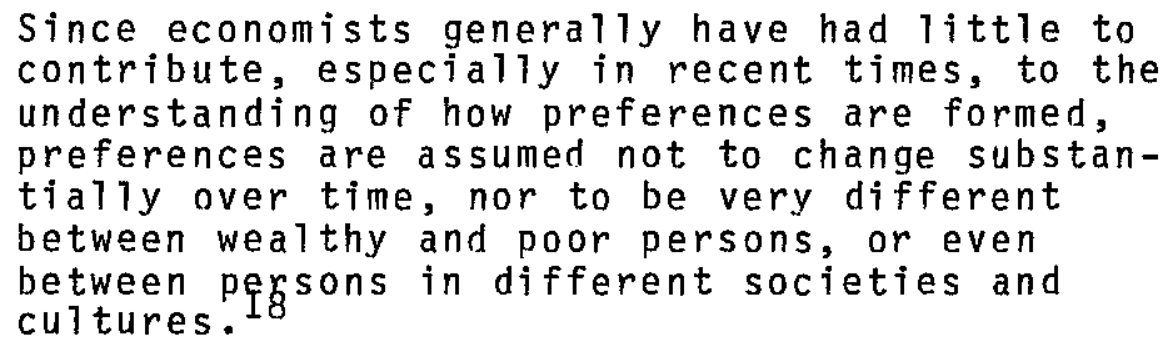

He goes on to make clear that the preferences whose stability is assumed relate not to market goods and services but to:

fundamental aspects of 1 ife, such as health, prestige, sensual pleasure, benevolence, or envy that do not always bear a stable relation

He feels, however, that such an assumption of stable preferences:

provides a stable foundation for generating predictions about responses to various changes, and prevents the analyst from succumbing to the temptation of simply postulating the required shift in preferences to "explain" al1 2 pparent contradictions to
his predictions.

He is scathing about economists who resort to such subterfuges and: 
the rather weak sense in which it purports to explain, is what its supporters must look for since it clearly cannot compete as an analysis of decision process. How well is this hope being, and likely to be, fulfilled? Obviously this will vary with the particular kind of case under consideration. One need not look for, or expect, a universal answer -- nor even a permanent one, as success is always relative to the alternative explanations available and these may change. However, in the four examples to which I now turn, my judgement is that the limited success in predicting behaviour will be insufficient to carry the day and that the evident incompleteness of the theory will call for richer and more complex approaches which pay more attention to motives and the ways in which decisions are made or actions precipitated.

The first two examples are concerned with the decisions of individuals about how to allocate their time. The first considers allocations to religious activity, the second to extramarital affairs. I have to admit some suspicion that the papers were written tongue in cheek, but if so they are executed cleverly enough to leave one in doubt. (There is one undoubted spoof on the economics of brushing teeth which I leave aside.24) The intentions of the authors are in any case largely irrelevant, and the very extravagance of their papers helps highlight the issues.

The paper on "Household Allocation of Time and Church Attendance" by Azzi and Ehrenberg 25 postulates a married couple 
future allocations of time and consumption in this life and an optimal expected utility stream in the afterlife.

The purpose of the model is, of course, to attempt to predict the response of current allocation decisions to changes in objective parameters, and to account for certain purported tendencies for churchgoing habits to differ by sex and age. Consider the latter first. How is the model supposed to explain the fact that women tend to spend more time churchgoing than do their husbands? by the fact that women"s wages are lower, so that women can produce afterlife consumption at lower opportunity cost providing they are not much less productive than men as producers of afterlife consumption. But the latter is an entirely gratuitous extra assumption so that the explanation is no explanation. Similarly, the tendency of churchgoing to rise with age is explained by the existence of a positive interest rate in the present life, on the quite gratuitous extra assumption that the rate of return on religious investment is less than this interest rate. Moreover even this will not suffice if the consumption motive for churchgoing is introduced.)

It transpires that the model has only two clear comparative static implications. One is that windfall increases in tangible assets will increase churchgoing -- providing after-life consumption acts as a normal good (but why should it?). The other is that the compensated response of current churchgoing to the current wage rate is negative. But this would no longer be true if afterlife consumption could also be obtained by charitable donation of goods (and why should it not be?). 
future apply with a vengeance, and applies a method of decision calculus appropriate only in circumstances where there is reasonable certainty, or at least uncertainty is manageable. And it ignores many of the social and emotional pressures which surround religion and make the assumption of stable independent preferences inappropriate. "Guilt" is one of many words that simply do not appear in the economist"s vocabulary. But I don"t want to denigrate the useful empirical work and acute observations to be found in the paper. Nor would I disagree with the proposition that whatever motives and pressures underly churchgoing there will tend to be less of it if its opportunity cost rises, other things the same. The economic point of view has that important, if obvious, insight to contribute.

I can deal somewhat more briefly with the second paper, "A Theory of Extra Marital Affairs" by Ray Fair.28 This is concerned with the decision of a married individual to spend his or her time with a paramour. To prove himself not an utter philistine, Fair quotes John Donne to the effect that variety is the spice of 1 ife and argues that:

since it is clear that variety is important in 1 ife, and since this idea is already one of the main motivations for the inclusion of more than one good in the utility function, there is an ample justification for applying it to leisure activities. This will ngy be done for two kinds of leisure activities. 29

The two leisure activities are time spent in one "s own household and time spent with a paramour. Time not spent in these two ways 
is based on rather inadequate data coming from voluntary reader response to sex questionnaires put out by pop-psychology magazines. One particular limitation of the data is that it contains no information on respondents" wage rates or assets, which can be only vaguely proxied by the information on educational attainment and occupation which is provided.

The statistical results show that frequency of extra-marital intercourse per year is significantly reduced by age and the reported degrees of marital happiness and religiosity, and significantly increased by the reported duration of marriage. Men and women do not seem to behave differentiy, nor do the number of children in the marriage seem to have an influence per se. The educational and occupational effects are inconclusive.

These results bear only the most tenuous relationship to the theory and are brought into consistency with it only by ex-post rationalisations such as "the negative significance of the religiosity variable means from the theory that utility from affairs declines with the degree of religiosity of the person." 31 Nevertheless, the results are claimed to "lend some support" to the theory. 32

My conclusion would be that the predictive value of the theory remains quite unproven, whereas its inability to give insight into motivation is blatant. Admittedly there are people who approach extramarital affairs in the same spirit as they approach buying a banana, but this is surely not universally so (although this type may be more likely to respond to magazine questionnaires). But even then the interactions of the three or 
calculus only by helping to determine the preference function or the threshold at which the individual takes his quietus. This theory suggests that suicide rates will tend to decrease with income and increase with age. The latter follows however from two rather arbitrary assumptions: that the current utility of income declines with age, and that the threshold is triggered, not by a low current rate of flow of utility, but by a low sum of current and expected future utility. Thus, someone might commit suicide now because of an adverse event expected in the remote future.

The statistical results do show that age and income have the expected kinds of effect and al so that suicide rates rise with unemployment, although this is interpreted as purely an income effect rather than a consequence of the depression, feelings of worthlessness, and so on, that often accompany job 1oss. The possible importance of non-economic factors is indicated by the finding that, even allowing for other differences, suicide rates in the restiess western states of the USA are higher than those for the rest of the country. The statistical analysis is ingenious but it owes very little to the detailed theory, which seems to offer minimal insight into the "whys and wherefores" of suicide. It is clear that economic events do have an influence on suicide rates, but this need not imply that suicide results from a considered and balanced appraisal of the person s future prospects. This may sometimes be so, as in the recent koestler case, but it may equally well be true that fear and despondency 
if they care sufficiently the optimal sorting will always pair them together. Moreover, since they care they may not adhere to the market-dictated distribution of benefits between them.

Becker claims that this approach has:

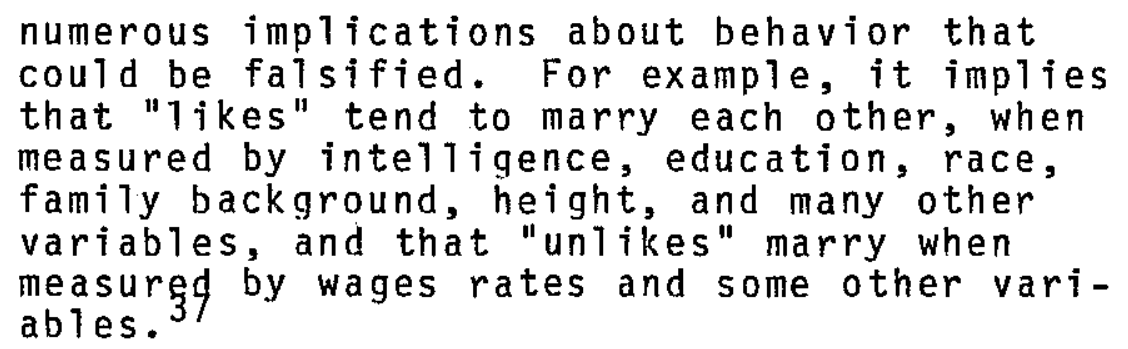

My impression, though, is that these implications can be inferred on1y by adding quite gratuitous extra assumptions about the nature of the unobservable production function for the intangible output.

My main criticism would not be with this aspect, however, but with the assumption that the marriage market attains equilibrium. True there are many potential spouses "out there, but to search among them is costly and time consuming, so that most people stop searching after exploring a relatively small number of possibilities. Also, "caring" is not something that exists in the abstract. One cannot take a man and woman at random and measure the caring that would exist or develop between them as a couple. Caring is only something that manifests itself during the search process. Not only will the market fail to reach equilibrium. This equilibrium itself becomes strongly pathdependent once caring is admitted. If we are going to successfully analyse "the marriage market" it will have to be as a 
A third kind of objection to the economic approach is that some actions are not deliberate, and based in some sense on persistent aspects of the individual's character, but are due to waywardness, passion, despondency, etc. I would certainly admit this and believe that such choices are unlikely to be expressible in terms of maximal choice from stable preferences, even though we attempt to average out across time or individuals. But even in such cases the opportunity costs of any action may prove to influence behaviour, although the channels through which they do so may remain mysterious. So even if one denies the applicability of the economist"s representation of human behaviour to some domains of behaviour, he might still play an important part by clarifying and identifying the opportunity costs of actions and stressing to other analysts the significance these costs may have in empirical explanation and prediction. 40

The "economics of human behaviour" stems from earler work on the determinants of planned pregnancies and decisions to acquire marketable ski11s. 41 such choices may reasonably be regarded as the product of a careful deliberation and the balancing of pros and cons. The economist"s approach to these problems has led to important insights. Moreover, improved understanding of the determinants of fertility and investment in human capital has promoted that understanding of narrowly-economic interactions which is the economist"s centrat concern. But one can push a good thing too far, with counterproductive consequences, and I fear that economists are doing just that as they strive to bring a11 aspects of human behaviour within their grasp. 
1. After delivering the lecture my attention was drawn to Harcourt (1978) which touches on closely related issues. Fortunately our respective efforts seem more complementary than competitive.

2. See Becker (1976).

3. A term borrowed from Kirzner (1960) who gives an extended account of the historical development of this viewpoint.

4. In dynamic contexts, where learning is necessary, this has to be relaxed. The individual needs sufficient knowledge of his environment to be aware of what he doesn"t know and how he might set about discovering it efficiently.

5. Cournot (1838).

6. See for example Arrow (1982), Baum (1983).

7. Keynes (1937), p. 124 .

8. Nerlove (1974), p. 209n.

9. See, for example, Margolis (1982). See also Sen (1982).

10. Wicksteed (1933), Vol. 1, pp. 170-183. On the bogy of "economic man" see Machlup (1972).

11. Margolis (1982).

12. Friedman (1953).

13. Again see Kirzner (1960) for an eloquent statement. A different but related plea for more emphasis on the procedures of decision making and for the development of a notion of procedural rationality is made in Simon (1978). Also see Bensusan-Butt (1978).

14. Becker (1976), p. 8 .

15. Ibid., p. 205.

16. Ibid., p. 5 .

17. Ibid., p. 7 .

18. Ibid., p. 5 .

19. Ibid., p. 5 . 
References

Arrow, Kenneth 3. (1982), "Risk Perception in Psychology and Economics," Economic Inquiry, 20 (Jan., 1982), 1-9.

Azzi, Corry and Ehrenberg, Ronald (1975), "Household Allocation of Time and Church Attendance," Journal of Political Economy, 83 (Feb., 1975), 27-52.

Baum, Sandra R. (1983), "The Role of Philosophical and Psychological Theory in Economics," paper presented to the 10th Annual Meeting of the History of Economics Society, Charlottesville, Virginia, May 1983.

Becker, Gary (1973-74), "A Theory of Marriage: Part I," Journa1 of Political Economy, 81 (July/August, 1973), 813-847; "A Theory of Marriage: Part II, "Journal of Political Economy, 82 (March/Apri1, 1974, Supplement), 11-26. (Both parts are reprinted in Becker (1976)).

Becker, Gary (1976), The Economic Approach to Human Behavior (Chicago, University of Chicago Press, 1976).

Bensusan-Butt, David M. (1978), On Economic Man: An Essay on the Elements of Economic Theory TCanberra, Australian National University Press, 1978).

Blinder, Alan (1974), "The Economics of Brushing Teeth," Journal of Political Economy, 82 (July/August, 1974), 887-891.

Cournot, Antoine Augustin (1838), Researches into the Mathematical Principles of the Theory of WeaTth TNew York, MacmiThan 1898: a translation of the French edition of 1838).

Fair, Ray C. (1978), "A Theory of Extramarital Affairs," Journal of Political Economy, 86 (Feb., 1978), 45-61.

Friedman, Milton (1953), "The Methodology of Positive Economics," Ch. 2 of his Essays in Positive Economics (Chicago, University of Chicago press, 1953).

Hamermesh, Daniel S. and Soss, Neal M. (1974), "An Economic Theory of Suicide," Journal of Political Economy, 82 (Jan./Feb., 1974), 83-98.

Harcourt, Geoffrey C. (1978), "The Social Science Imperialists," Annual Lecture to the Academy of the Social Sciences in Australia, Canberra, 1978. Reprinted in his The Social Science Imperialists (London, Routledge, Kegan and PauT, 1982.) 